\title{
Abraham Janssens y su Lamentación sobre Cristo muerto: una copia de taller inédita en España
}

\author{
Antonio Romero Dorado \\ Universidad de Sevilla \\ antonio.romero.dorado@gmail.com
}

Con este texto damos a conocer una nueva obra del pintor flamenco Abraham Janssens conservada en España. Se trata de la Lamentación sobre Cristo muerto [1] que alberga la Iglesia Mayor de Sanlúcar de Barrameda, en Andalucía'. Esta pintura, hasta ahora inédita, está realizada al óleo sobre lienzo y mide aproximadamente 150 × 230 centímetros (su elevada ubicación nos ha impedido tomar las medidas exactas). En su formato apaisado se representa el cuerpo muerto de Cristo acompañado por la Virgen, San Juan, la Magdalena, José de Arimatea y una de las santas mujeres. Estamos ante una copia de la pintura del mismo asunto conservada en el Museo Nacional de Varsovia (Número de inventario M.Ob.1680 MNW) [2].

El motivo principal de la pintura es el cadáver de Jesús, colocado sobre lo que parece la losa del sepulcro y una voluminosa almohada, ambas cubiertas por una sábana blanca. La anatomía de Cristo se muestra poderosa, sobre todo en piernas y brazos, resultando algo más mórbida en el torso. La carnación usada, apenas interrumpida por un paño que tapa la zona inguinal, es clara y uniforme, salvo en el rostro, manos, pies y rodillas, que presentan evidentes matices verdosos. Se muestra una imagen incruenta de Jesús, con toda la piel y las llagas limpias de sangre. De hecho, se plasma el momento en que la limpieza del cuerpo ha finalizado, como delata la palangana de metal dorado de la esquina inferior izquierda.

A la derecha del recipiente, hay una hoja de papel con una leyenda que dice "Jesús Nazareno rey de los judíos", escrita en hebreo, griego y latín. En el centro del cuadro, la Magdalena está vestida de un violeta extremadamente pálido y está cubierta por un manto amarillo mostaza, que parece de tafetán. La santa, que está de rodillas, acerca la mano llagada de Cristo a sus labios, en ademán de besarla, usando un lienzo blanco para sostener respetuosamente el brazo. Su cabello es rubio cobrizo y queda recogido en un moño alto, aderezado con una cuerda bicolor de seda torcida. Los efectos del llanto se perciben en su pálido rostro, que presenta zonas enrojecidas. Por su parte, la Virgen aparece arrodillada a los pies de su hijo, en el extremo derecho de la pintura. Está completamente cubierta por un gran manto azul oscuro, bajo el que aflora la toca y las mangas del vestido, de color blanco. Con las manos entrelazadas a la altura del regazo y el enrojecido rostro hacia el frente, dirige su mirada hacia arriba, en actitud de ensimismada plegaria. San Juan, en un plano posterior, está entre la Virgen y la Magdalena, con túnica oscura y manto rojo. Su pelo castaño aparece peinado con la raya en medio y en su rostro se aprecia una incipiente barba. Con los dedos unidos en gesto de oración, se asoma por detrás de la Magdalena, como buscando su sitio para contemplar a Cristo.

Por último, en el ángulo superior izquierdo, en el mismo plano de profundidad que San Juan, están representados José de Arimatea y una de las santas mujeres. El santo varón, cuya barba es larga y cana, viste una túnica encarnada, apenas visible, y lleva un gorro de tela oscura. La mujer, de cuello algo rollizo y mejillas encendidas, viste una túnica blanca con una bata encima de color verde intenso y cubre su pelo oscuro con un vistoso turbante de color verde amarillento, cuyo tejido a rayas suele emplearse para plasmar la indumentaria de los judíos. La mujer, que une sus dedos índices, dirige la mirada y parece decir algo a Arimatea, mientras este mira la mano de Cristo besada por la Magdalena y realiza un gesto con la mano derecha.

En cuanto a las líneas compositivas, destaca con claridad la diagonal que describe la figura de Cristo. Asimismo, tiene un gran protagonismo el conjunto formado por Jesús y la Magdalena, que crean un triángulo que se aprecia si unimos con líneas imaginarias la cabeza de la santa con la 
cabeza y los pies de Cristo. La introducción de la palangana en el ángulo inferior izquierdo parece querer compensar el desequilibrio del mencionado triángulo, transformándolo en una estable pirámide. Por otro lado, también se observa una línea circular que une la cabeza de la Magdalena, la de Cristo, su costado, la pierna y ambas rodillas, para volver a la cabeza de la Magdalena, recorriendo todo el contorno de su espalda. Además, a excepción de la figura de la Virgen, que se muestra a la derecha, rotunda y yuxtapuesta, el resto de las imágenes queda claramente supeditado a este grupo central. Por todo ello, afirmamos que la composición tiene varias líneas claras pero también presenta cierta ambigüedad o ambivalencia de raigambre manierista. Asimismo, debemos observar el marco de la pintura, datable en el siglo XVII, que está pintado en color marrón de matiz encarnado y que presenta una fina moldura dorada tallada en forma de hojas y apliques de roleos vegetales, en las esquinas y partes centrales.

La variedad de actitudes de los personajes, las múltiples relaciones compositivas que se establecen entre ellos, la diversidad cromática y el elaborado tratamiento de los diferentes tejidos y de sus pliegues, hacen de esta pintura una obra verdaderamente interesante, cuya calidad final sin embargo es difícil de apreciar, por su mala ubicación y pésimo estado de conservación. Hasta mediados de 2016 (fecha en la que se ha adecentado) la obra presentaba un aspecto lamentable [3]. El lienzo tenía algunas roturas por impacto y desgaste por rozamiento. Lo peor era el aspecto blanquecino y apagado que mostraba toda la capa pictórica. A pesar de ello, la composición se distinguía con bastante claridad, lo que nos permitió poner en relación este cuadro de Sanlúcar con el de Varsovia ${ }^{2}$.

Esta última se creía procedente de la iglesia de los Carmelitas Calzados de Amberes, concretamente del altar funerario de Magdalena van Woonsel, realizado a instancias de su marido, Aegidius Fabri. En consecuencia la obra se había datado hacia 1622 y el protagonismo que en la composición tiene la Magdalena se explicaba por ser la santa patrona de la señora van Woonsel (Benesz, 2001: 200-210). Sin embargo, en 2007 Joost Vander Auwera descubrió que el Entierro de Cristo procedente de los Carmelitas de Amberes realmente se encuentra en Iglesia de San Pedro de Denderwindeke (localidad de Ninoove), lo que encaja mucho mejor con el estilo de su pendant, la Virgo inter Virgines con- servada hoy en la Catedral de Lyon. No obstante, aunque la procedencia del original de Varsovia se desconoce, el estilo y los tipos humanos están muy cerca de la Crucifixión del Museo de Bellas Artes de Valenciennes (Número de inventario: Inv. 46-1-13), datado hacia 1624 (AAW, 2016: ficha n. $\left.{ }^{\circ} 338\right)$, fecha en la que podemos fechar la Lamentación de Varsovia.

Janssens fue un pintor activo en Amberes, posiblemente formado con Jan Snellinck. Viajó a Italia, donde entró en contacto con el caravaggismo, incorporando el lenguaje de esta corriente a su formación inicial, de raíz manierista. En 1602 ya pertenecía al Gremio de San Lucas de Amberes, del que se convertiría en decano en 1607, llegando a ser uno de los pintores más conocidos de la ciudad, para luego caer bajo la influencia de Rubens (Müller, 1971: 208-303). En los cuadros de Varsovia y de Sanlúcar todavía observamos el influjo del naturalismo caravaggista, en los gestos de San Juan, Arimatea y la santa mujer, así como en el fondo, profundamente negro.

Si comparamos la pintura de Sanlúcar con la de Varsovia, apenas se perciben ligeras diferencias. El grupo de figuras es exactamente el mismo y la única desigualdad está en un detalle mínimo. Se trata del clavo que aparece junto a la palangana, que está en Varsovia pero no en Sanlúcar. Sin embargo, la principal desigualdad se observa en los márgenes de ambas pinturas, que en Sanlúcar son más amplios que en Varsovia, tanto a izquierda como a derecha. Esta mayor amplitud es especialmente notable en el margen derecho, lo que permite que la figura de la Virgen se desarrolle por completo y añade en la esquina superior derecha una gran superficie al fondo, en la que se aprecia el sepulcro abierto y un sucinto fondo vegetal. Por el contrario, el margen superior en Sanlúcar es ligeramente más estrecho que en Varsovia. Lo cierto es que la pintura conservada en Polonia mide 155 x 180,5 cm mientras que la española tiene aproximadamente $150 \times 230 \mathrm{~cm}$.

Afortunadamente disponemos de un estudio técnico de la pintura de Varsovia (Janczarski, 2001: 211-216), realizado durante la restauración a la que fue sometida. Gracias a ello conocemos muchos aspectos del proceso creativo de la obra. En primer lugar, sabemos que los laterales fueron recortados en algún momento. Del mismo modo, que el cuadro polaco tiene un pequeño añadido en la zona superior. Ambas modificaciones en el formato encajan con lo 


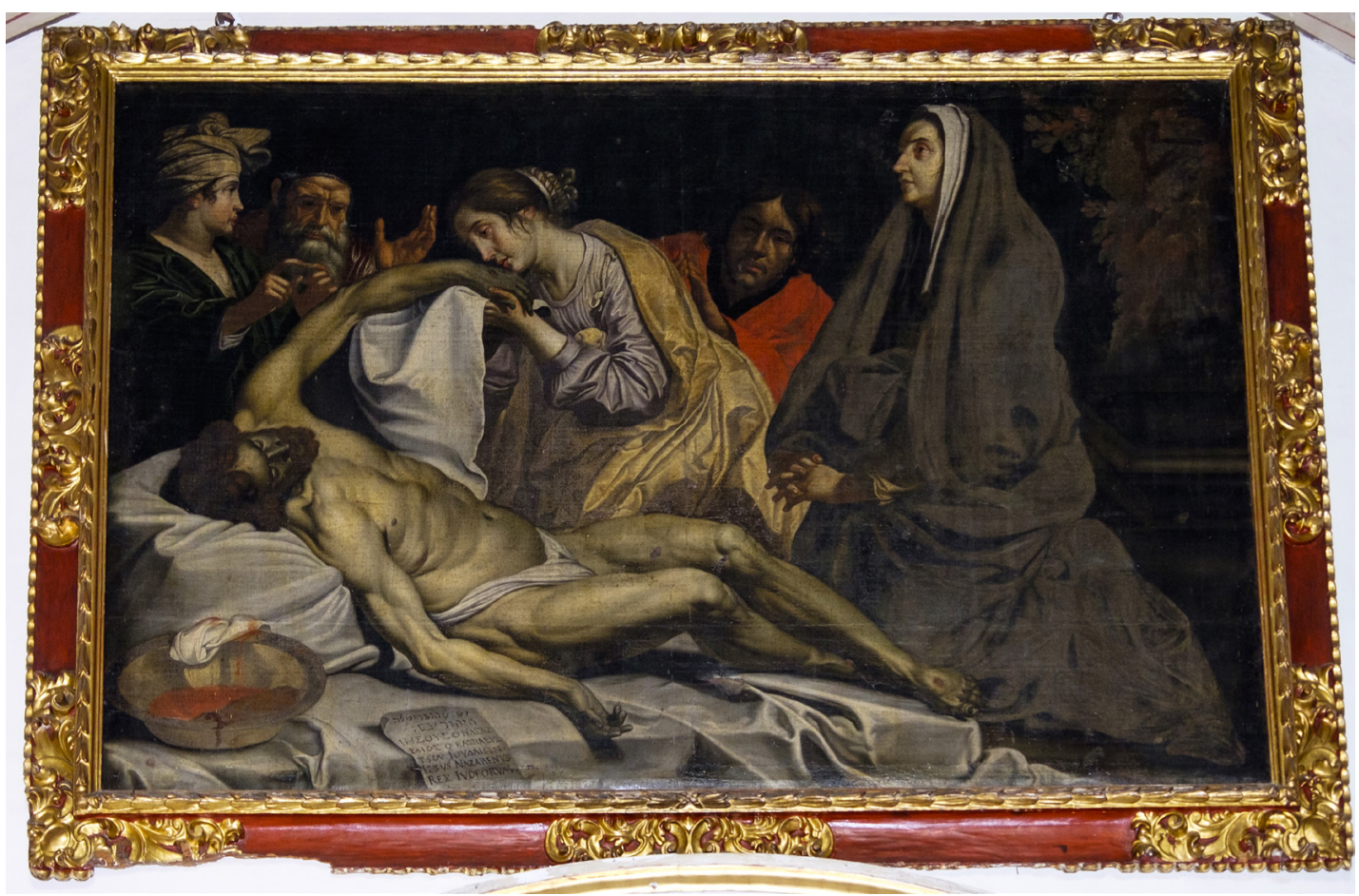

1. La Lamentación sobre Cristo muerto, taller de Abraham Janssens, entre 1622 y 1632, Iglesia Mayor de Sanlúcar

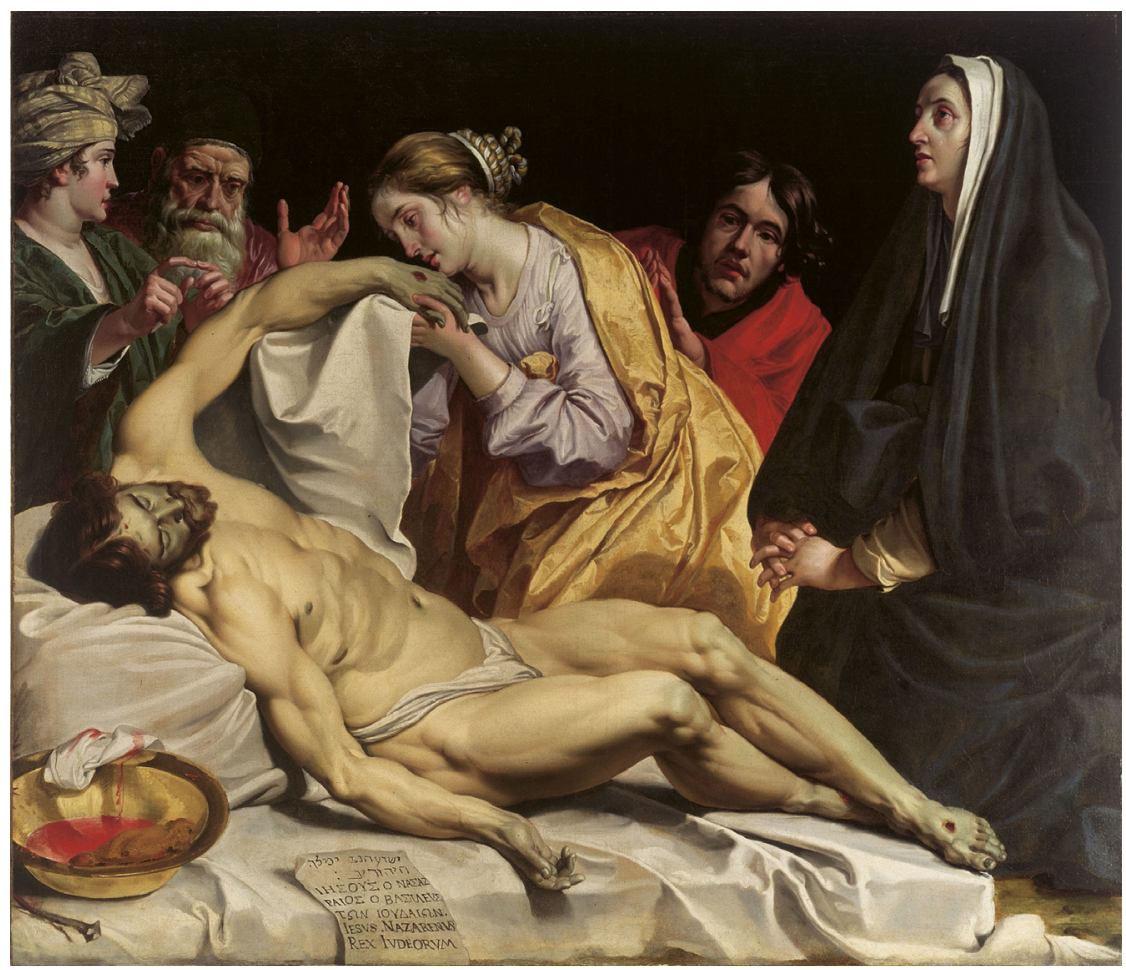

2. La Lamentación sobre Cristo muerto, Museo Nacional de Varsovia, ha. 1624 


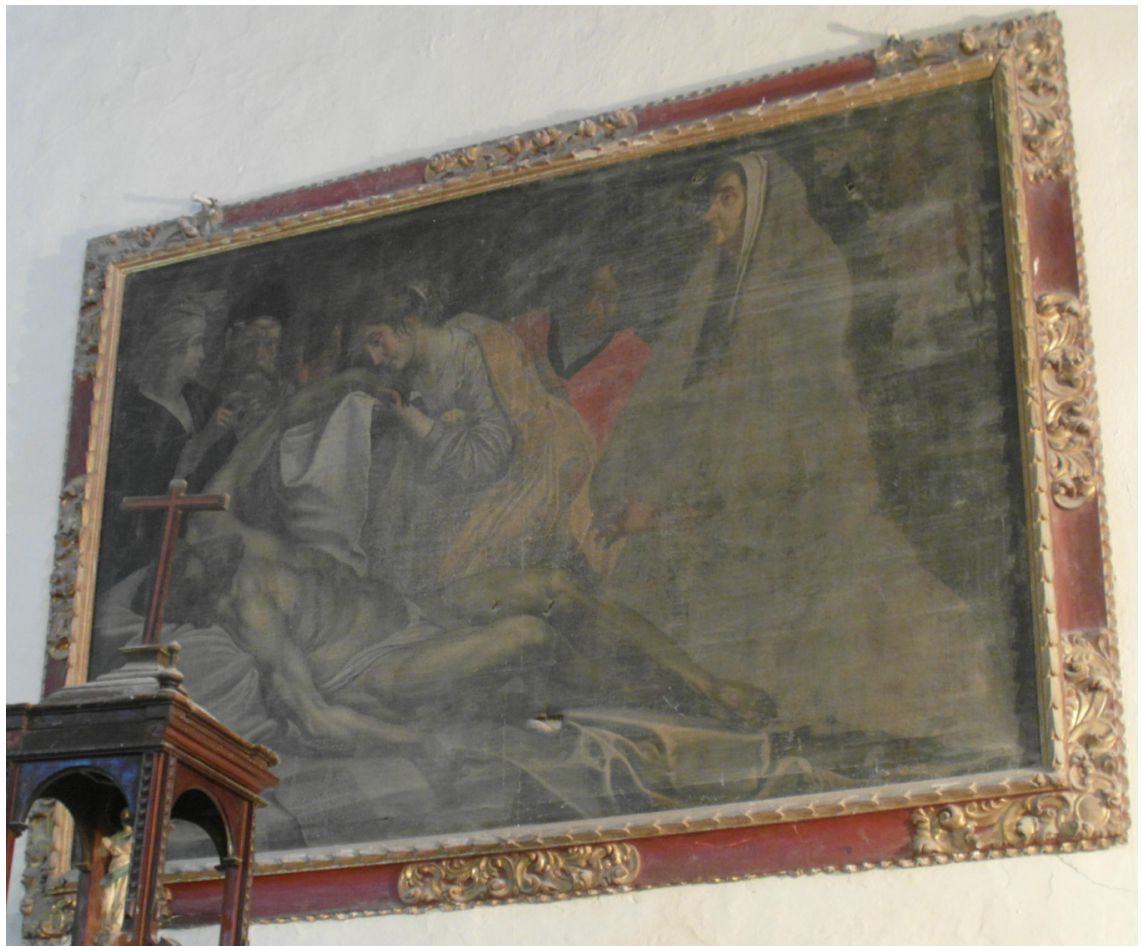

3. La Lamentación sobre Cristo muerto, Sanlúcar, estado de conservación anterior a julio de 2016 que observamos en Sanlúcar, si bien ahora sabemos que la pintura de Varsovia está mutilada principalmente por el lado derecho, no por el izquierdo, como habían supuesto sus restauradores.

El estudio técnico también ha descubierto bajo la superficie de la obra de Varsovia algunos arrepentimientos de Janssens, en concreto en la mano y en la cabeza de Arimatea. También que se trata de un cuadro pintado enteramente al temple y no al óleo, siendo esto último lo habitual en la pintura flamenca del siglo XVII. Esta peculiaridad explica la intensidad del colorido de la obra de Varsovia, que no se percibe en Sanlúcar. El estudio, además, ha desvelado una gran unidad y calidad en la ejecución, que sugiere una participación casi exclusiva del maestro, sin el concurso de ayudantes. Lo cierto es que pintar al temple sobre tela requiere que se aplique una preparación muy resistente al agua y demanda del pintor un gran virtuosismo, pues reclama una ejecución alla prima, mucho menos susceptible de retoque que el óleo.

Todo lo anterior nos lleva a creer que la Lamentación de Sanlúcar es una réplica realizada en el propio taller de Janssens. La dificultad técnica del temple sobre lienzo debió determinar que se eligiera el óleo para realizar una segunda versión de la obra. En ella presuponemos una mayor participación de los ayudantes, que pudieron usar un calco del original de Varsovia, lo cual era una práctica bastante habitual en los obradores. Además, los arrepentimientos que subyacen en el cuadro polaco también indicarían que se trata de una primera versión, pues la pintura de Sanlúcar es idéntica en superficie a la polaca (salvo el detalle del clavo junto a la palangana que ya hemos indicado). En consecuencia, la de Sanlúcar no parece una simple copia del modelo de Janssens, sino que se trataría de un "Janssens de taller», que debemos fechar entre 1624 y 1632, año aproximado de la creación del original y de la muerte del artista, respectivamente.

Para finalizar, ignoramos de dónde procede la pintura de Sanlúcar, así como cuándo y cómo llegó a España. Puede que dichas incógnitas no se despejen nunca, pero queda de manifiesto la importancia que tiene el estudio comparativo de las copias, que en este caso nos permite conocer el estado primigenio de un original que tiene graves alteraciones. Por ello, esta nueva pintura de Janssens reclama una rigurosa restauración científica. 


\section{Notas}

1 Queremos agradecer su imprescindible ayuda a D. ${ }^{a}$ Hanna Benesz y D. ${ }^{a}$ Aleksandra Janiszewska y D. Mikołaj Machowski, del Museo Nacional de Varsovia, y a D. Joost Vander Auwera, de los Reales Museos de Bellas Artes de Bélgica, en Bruselas. Asimismo agradecemos al sacerdote D. Juan Jacinto del Castillo Espinosa habernos permitido fotografiar la obra, que hasta mediados de 2016 estuvo en el coro alto del templo, en el lado de la Epístola, frente al órgano. Actualmente está en la capilla de las Ánimas, en el lado de la Epístola.

2 Así se lo revelé a D. Eduardo Lamas Delgado, quien lo trasmitió a D. a Ana Diéguez Rodríguez, que junto a D. Matías Díaz Padrón visitaron Sanlúcar y vieron la obra. A todos agradezco el interés por mi trabajo y a D. ${ }^{a}$ Ana por su ayuda con la bibliografía.

\section{Bibliografía}

AA.W. (2016), Early Netherlandish, Dutch, Flemish and Belgian Paintings 1494-1983 in the Collections of the National Museum in Warsaw and the Palace at Nieborów. Complete Illustrated Summary Catalogue, Varsovia.

BENESZ, Hanna (2001-2002), «A painting in the National Museum in Warsaw identified as the Entombment by Abraham Janssens from the Church of the Calced Carmelites in Antwerp», Oud Holland, vol. 115, n. ${ }^{\circ}$ 3-4, pp. 200-210.

JANCZARSKI, Grzegorz (2001-2002), «Technical Analysis of Abraham Janssens' Entombment in the National Museum in Warsaw», Oud Holland, vol. 115, n. ${ }^{\circ} 3-4$, pp. 211-216.

MÜLLER HOFSTEDE, Justus (1971), «Abraham Janssens: zur Problematik des flämischen Caravaggismus», Jahrbuch der Berliner Museen, n. 13 , pp. 208-303. 
